\title{
Preface: Articulatory Phonology
}

When organizing a previous special issue 'On the Relation between Phonetics and Phonology' [Phonetica, vol. 48/2-4/19,91], I had intended to invite Catherine P. Browman and Louis Goldstein to contribute a paper summarizing their important work on articulatory phonology. On further reflection, however, it became evident that the theory of articulatory phonology had reached a sufficient level of development - and had provoked sufficient interest among phoneticians, phonolo-gists, and other scientists - to warrant a special issue of its own. Browman and Goldstein kindly agreed to submit a target article presenting an overview of the theory and relevant empirical data, and to have their work subjected to critical evaluation in an 'open peer commentary' format. Four invited commentaries on the target article were prepared by George N. Clements, John Kingston and Avis H. Cohen, Klaus J. Kohler and Celia Scully. Finally, Browman and Goldstein were given an opportunity to respond to the commentaries. I hope readers will agree that the overall result is a highly productive discussion of some fundamental issues in phonetics and phonology.

Cathe and Louis and the five commentators are all to be applauded for the intellectual seriousness with which they approached their respective tasks.

Randy L. Diehl

Editor for North America

153 